\title{
Lipoprotein (a) level in the population in Taiwan: relationship to sociodemographic and atherosclerotic risk factors
}

\author{
Kuo-Liong Chien a, Yuan-Teh Lee ${ }^{\text {a,* }}$, Fung-Chang Sung ${ }^{\text {b }}$, Ta-Chen Su ${ }^{\text {a }}$, Hsiu-Ching Hsu ${ }^{\text {a }}$, \\ Ruey-Shiung Lin ${ }^{\mathrm{b}}$ \\ a Department of Internal Medicine, National Taiwan University College of Medicine, National Taiwan University, Taipei 100, Taiwan, ROC \\ ${ }^{\mathrm{b}}$ College of Public Health, National Taiwan University, Taipei 100, Taiwan, ROC
}

Received 26 June 1998; received in revised form 5 September 1998; accepted 3 November 1998

\begin{abstract}
To examine the lipoprotein(a) (Lp(a)) level in the Taiwanese population and its association with cardiovascular risk factors, 1703 men and 1899 women aged 35 years and above were enrolled in a community-based study cohort established between 1990 and 1991. The distributions of Lp(a) levels were skewed to the right, and females were more likely than males to have Lp(a) levels greater than $30 \mathrm{mg} / \mathrm{dl}(14.3 \%$ versus $11.6 \%, P<0.05)$. The $\mathrm{Lp}$ (a) level increased with age. Socioeconomic status did not seem to have consistent influence on the level of Lp(a). Smoking and alcohol use also had no effect on Lp(a) levels. Multivariate analysis indicated that older age and high level of low-density-lipoprotein cholesterol corresponded to an elevated Lp(a) level, while hypertriglyceridemia, low high-density-lipoprotein cholesterol level, obesity and high insulin resistance corresponded to a lower Lp(a) level. In univariate analysis, hyperinsulinemia was negatively associated with Lp(a) level $(-0.107, P<0.01)$ only in males. In females, use of oral contraceptive lowered Lp(a) levels, but menopause did not change Lp(a) levels. We also found that different correlation patterns existed for selected coagulation profiles between sexes. There was a significant correlation between $\mathrm{Lp}$ (a) and fibrinogen levels in males $(0.154, P<0.001)$ but not in females $(0.007, P>0.05)$. These data provided clues for investigating atherosclerotic risk factors and coagulation parameters for the Taiwanese population. (C) 1999 Elsevier Science Ireland Ltd. All rights reserved.
\end{abstract}

Keywords: Lipoprotein(a); Atherosclerosis; Taiwanese; Population-based

\section{Introduction}

Lipoprotein(a) (Lp(a)), consisting of low density lipoprotein and apolipoprotein(a) with disulfide binding, has been well established as a cardiovascular risk factor $[1,2]$. Apolipoprotein(a) is a glycoprotein with its DNA locus on the sixth chromosome, near the plasminogen loci that has size polymorphism [3]. The structure of apolipoprotein(a) is similar to plasminogen; it can interfere with hemolytic functions and increase the time required for clot hemolysis by competing with the

\footnotetext{
* Corresponding author. Tel.: + 886-2-23959911; fax.: + 886-223959911.

E-mail address: ytlee@ha.mc.ntu.edu.tw (Y.-T. Lee)
}

plasminogen receptor[4]. Found in the arterial walls of patients with coronary artery disease, according to experimental studies, $\mathrm{Lp}(\mathrm{a})$ can penetrate the intimal layers of vessel walls to stimulate foamy-cell production and is considered a risk factor in atherogenesis and thrombosis. Along with excess serum low-density lipoprotein cholesterol (LDL-C) or other risk factors, Lp(a) may synergistically contribute to the incidence of cardiovascular disease[5].

Although Lp(a) levels have strong genetic links and are neither affected by life style nor altered by medication[6], factors associated with $\mathrm{Lp}$ (a) concentrations and other atherosclerotic risk factors remain elusive. The Framingham offspring study demonstrated that serum $\mathrm{Lp}$ (a) concentration increased with age, only in 
women [7]. Correlations with other atherosclerotic risk factors, such as sex, smoking, waist-to-hip ratio, impaired glucose tolerance, selected medications, fibrinogen levels, and blood pressure, have also been demonstrated [8-10]. However, most studies are hospital-based or employee-based [11] and limited data are available for Asian populations. Only a few studies on Chinese ethnic groups are available and have provided inconsistent data on $\mathrm{Lp}(\mathrm{a})$ due to small sample size $[12,13]$.

The Chin-Shan Community Cardiovascular Cohort (CCCC) study is a population-based prospective investigation on the impact of atherosclerotic risk factors in the development of cardiovascular diseases in adults 35 years of age and older. This report attempted to determine the $L p(a)$ distribution for this cohort in which a large number of demographic, cardiovascular, lipid profiles and other hemostatic parameters were available. Evaluations emphasize the correlations between these variables.

\section{Materials and methods}

\subsection{Study design and population}

The study cohort, consisting of 1703 men and 1899 women, 35 years old and above, was established in 1990 and 1991. All were recruited based on 1990 residential registration files $(N=4399)$ in the Chin-Shan community, a suburban community 20 miles outside of metropolitan Taipei. The response rate was $82.8 \%$. Among the non-respondents, 95 were refusals and 652 could not be reached, based on the registration, and were somewhat younger than respondents. The current report uses baseline data collected in 1990-1991, and ultrasound results and coagulation profiles collected in 1992-1993. The leading causes of deaths, mainly from cardiovascular disease and cancer in this community, mirror national mortality patterns in Taiwan between 1990 and 1994 [14].

\subsection{Data collection and interpretation}

A clinic was set up at the Chin-Shan Community Health Center by a study team consisting of 20 senior medical students, two assistant nurses and 10 cardiologists and local practitioners. Trained medical students canvassed door-to-door with the assistance of community leaders to extend invitations for the baseline survey. Information collected included sociodemographic characteristics, lifestyle, dietary characteristics, personal and family histories of diseases and hospitalizations, etc. With the consent of participants, the team of physicians and students con- ducted physical examinations and laboratory tests on those participants invited to the clinic. A 12-lead electrocardiography was also performed for each participant, and the result was evaluated by a cardiologist.

\subsection{Blood sampling and analytical methods}

All venous blood samples were drawn after a 12-h overnight fast, immediately refrigerated and transported to National Taiwan University Hospital within $6 \mathrm{~h}$. Serum samples were then stored at $-70^{\circ} \mathrm{C}$ prior to batch assay of the concentrations of total cholesterol, triglyceride, LDL-C, high density lipoprotein cholesterol (HDL-C), and Lp(a) [15]. Standard enzymatic tests for serum cholesterol and triglyceride were used (Merck 14354 and 14366, respectively). HDL-C levels were measured in supernatants after precipitation with magnesium chloride phosphotungstate reagents (Merck 14993). LDL-C concentrations were calculated as 'total cholesterol minus cholesterol in the supernatant' by the precipitation method [16], since the HDL-C was precipitated using heparin/citrate reagent (Merck 14992). Apolipoprotein A1 (apo A1) and apolipoprotein B (apo B) concentrations were measured by turbidimetric immunoassay using commercial kits (Sigma). Lp(a) was determined by enzyme-linked immunosorbent assay (ELISA) (Organon) regardless of isoforms. The plasma insulin level was determined using the ELISA method in which a reagent kit supplied by Dako is employed. The plate antibody binds A-chains somewhere near the intrachain disulphide. The conjugate antibody binds very close to the cleavage site in proinsulin and its epitope is partially composed of lysine residue at position 30 on the B-chain. Thus, the assay will not measure intact proinsulin, but provides specificity of the insulin assay [17].

\subsection{Coagulation profile measurement}

The measurements of coagulation profiles were made in the following manner: Tissue plasminogen activator (TPA) was analyzed using enzyme immunoassay (Asserachrom tPA, Diagnostica Stago, France), and plasminogen activator inhibitor (PAI-1), Factor VII antigen, and fibrinogen were measured using commercial kits. PAI-1 was measured using enzyme immunoassay (Asserachrom PAI-1, Diagnostica Stago, France). Factor VII antigen was measured using enzyme immunoassay (Asserachrom VII: Ag, Diagnostica Stago, France). Fibrinogen was measured using clotting assay (STA-Fibrinogen, Diagnostica Stago, France). Factor VIII concentration was measured using single-stage assay [18]. 


\subsection{Diagnostic criteria}

Hypertension was defined according to the criteria established by the Fifth Joint National Committee on Detection, Evaluation and Treatment of High Blood Pressure [19]. We adapted the following criteria: systolic blood pressure higher than $140 \mathrm{mmHg}$ or diastolic blood pressure higher than $90 \mathrm{mmHg}$, and/or receiving anti-hypertensive medication. The presence of coronary heart disease was defined as the presence of abnormal $\mathrm{Q}$ or QS patterns on electrocardiograms, or clinical histories of myocardial infarction or angina pectoris, based on medical records. Stroke was defined as hemiparesis or hemiplegia histories, and confirmed by a neurologist. Diabetes mellitus was defined as fasting blood sugar levels higher than $140 \mathrm{mg} / \mathrm{dl}$ or use of oral hypoglycemic agents or insulin injections. The 90th percentile values of body-mass indices (BMI) and waistto-hip ratios (WHR) were considered normal for the study population. Hyperinsulinemia was defined as fasting insulin levels greater than the 90th percentile values for each gender. Mathew's homeostasis modeling formula for insulin resistance were calculated [20]. Women older than 45 years with secondary amenorrhea for longer than 1 year were defined as in menopausal status.

\subsection{Statistical analysis}

We first compared the distribution pattern of serum $\mathrm{Lp}$ (a) concentrations by age and gender. Because of the highly right-skewed distribution of $\mathrm{Lp}$ (a) values, the natural logarithm of $\mathrm{Lp}$ (a) was used to normalize its distribution to satisfy analysis of covariance assump- tion. Gender- and age-specific quartiles of $L p(a)$ values were generated from logarithmically transformed $L p(a)$. Age-adjusted geometric means of $L p(a)$ by gender were also calculated to measure the effects of lipid level, BMI, WHR and hyperinsulinemia. The total cholesterol and LDL cholesterol cut-off points were according to NCEP guidelines. Both the 75th and 90th percentile cut-off points were used for the rest of the variables (Table 2). A Spearman correlation analysis was performed to measure the linear relationship between covariates and L(a) values. One-way analysis of covariance with adjustment for age was employed for comparison of the mean values. When using parametric procedures, triglyceride and $\mathrm{Lp}$ (a) levels were transformed into natural logarithms. A significant difference was defined at $P<0.05$. Several optional multivariate analysis models were further developed using either stepwise regression or Mallows' $\mathrm{C}(\mathrm{p})$ method to summarize factors contributing to the Lp(a) level [21]. Data analysis was performed using the SAS 6.11 version [22].

\section{Results}

The empirical distribution of serum $\mathrm{Lp}$ (a) levels for the study population clearly demonstrated a right skewed shape, ranging widely from 0.11 to $116.9 \mathrm{mg} / \mathrm{dl}$ in men, and from 0.11 to $129.4 \mathrm{mg} / \mathrm{dl}$ in women (data not shown). The $L p(a)$ values were undetectable in $1.0 \%$ of the males and $0.8 \%$ of the females. Table 1 details the gender- and age-specific distributions and the proportions of $L p(a)$ greater than $30 \mathrm{mg} / \mathrm{dl}$. As age increased, the $\mathrm{Lp}$ (a) levels increased in both genders, peaking at 65-74 years of age for men (geometric mean

Table 1

The distribution of lipoprotein(a) levels $(\mathrm{mg} / \mathrm{dl})$ in the study population by sex and age: the Chin-Shan Community Cardiovascular Cohort Study, 1990-1991

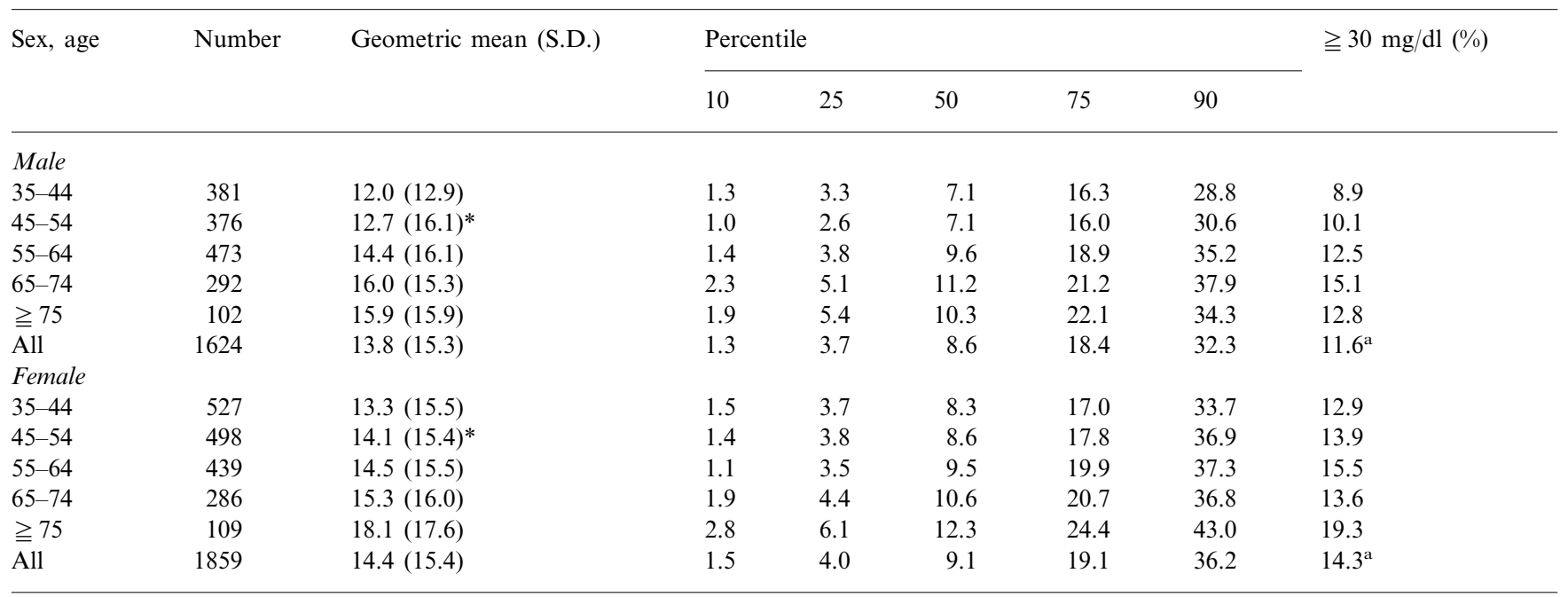

$* P<0.05$ by the unpaired t-test for males versus females in the $45-54$ years age group.

${ }^{\text {a }}$ Difference between each sex: $2.7 \%, 95 \%$ confidence interval: $(0.6 \%, 4.9 \%)$. 
Table 2

Age-adjusted geometric mean of lipoprotein(a) $(\mathrm{mg} / \mathrm{dl})$ by atherosclerotic risk factor in the study population: the Chin-Shan Community Cardiovascular Cohort Study, 1990-1991

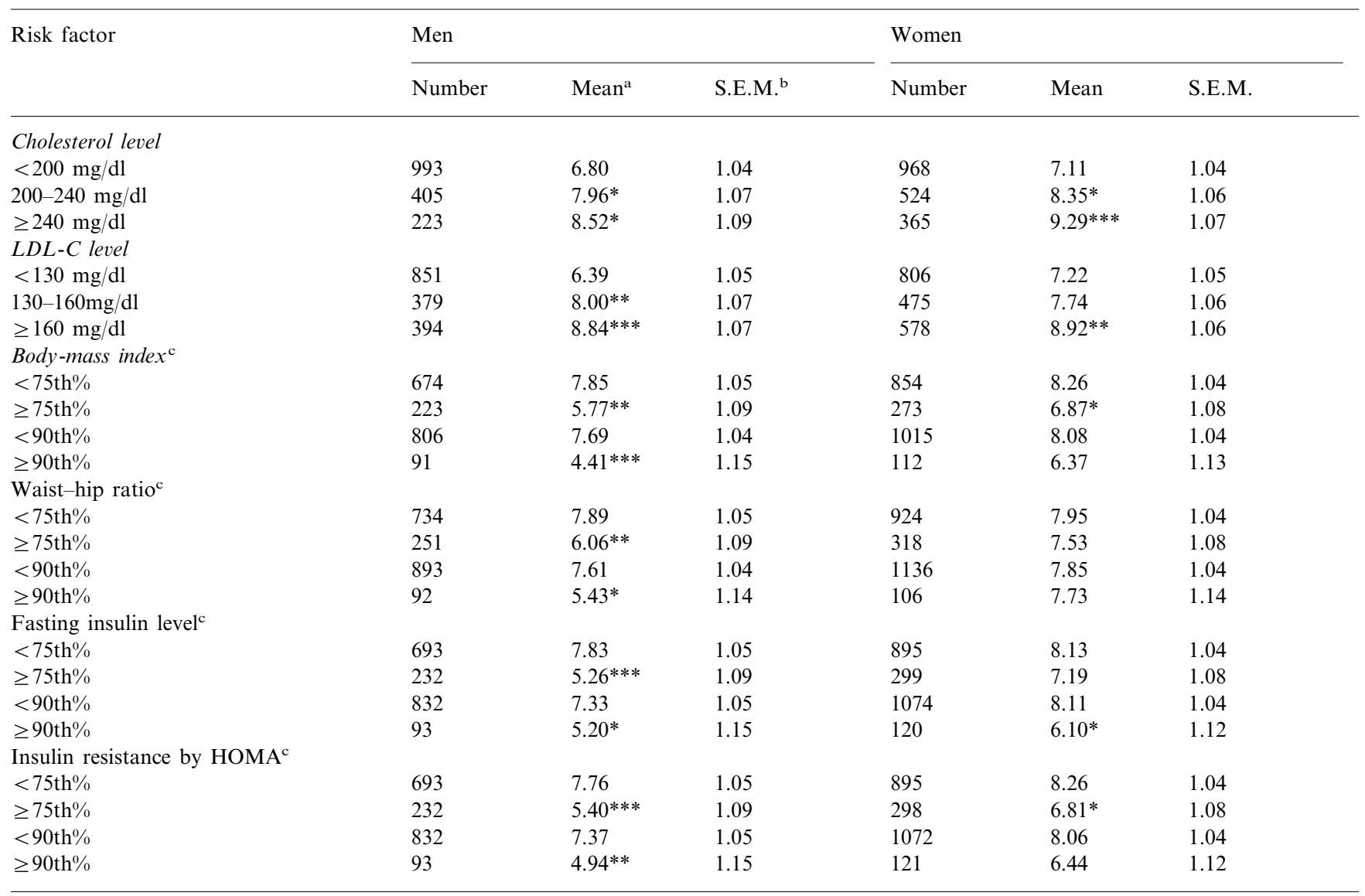

${ }^{a}$ Geometric mean.

b S.E.M., standard error of mean.

* $P<0.05$, compared for counterpart stratum by genders.

** $P<0.01$, compared for counterpart stratum by genders.

*** $P<0.001$, compared for counterpart stratum by genders.

${ }^{\mathrm{c}}$ Sex-specific 75 th or 90 th percentile value.

$16.0 \mathrm{mg} / \mathrm{dl})$ and 75 years of age or above for women (geometric mean $18.1 \mathrm{mg} / \mathrm{dl}$ ). Generally, geometric means of $L p(a)$ levels were higher in females than in males, and the difference was statistically significant for the 45-54 age group. The proportion of individuals with $30 \mathrm{mg} / \mathrm{dl} \mathrm{Lp(a)} \mathrm{or} \mathrm{greater} \mathrm{also} \mathrm{increased} \mathrm{as} \mathrm{age}$ increased and was greater in females than in males $(14.3 \%$ versus $11.6 \%, P<0.05)$, with the greatest difference in the oldest group $19.3 \%$ in women and $12.8 \%$ in men, $P<0.05$ ).

Analyses also attempted to distinguish age-adjusted Lp(a) levels by smoking, drinking, educational attainment, marital status and occupation. Decreased levels were found for male government employees, teachers and businessmen $(5.80 \mathrm{mg} / \mathrm{dl}$ for white-collar workers versus $7.92 \mathrm{mg} / \mathrm{dl}$ for blue collar workers, $P<0.01$; data not shown).

Table 2 shows age-adjusted Lp(a) concentration distributions by gender and selected atherosclerotic risk factors. The geometric means of $\mathrm{Lp}$ (a) were significantly elevated for both men and women with higher levels of cholesterol, LDL-C and triglyceride or lower HDL-C level. The obese group (BMI 90th percentile) exhibited a significant lower $\mathrm{Lp}(\mathrm{a})$ level than the nonobese group, regardless of sex. This association was significant for males only when the central-obesity group was defined as having a waist-to-hip ratio at the 90th percentile or greater that had lower Lp(a) levels (5.43 mg/dl versus $7.61 \mathrm{mg} / \mathrm{dl}, P<0.05$ ).

Table 2 also shows that individuals with hyperinsulinemia had much lower $L p(a)$ levels than non-hyperinsulinemics, significant for both men $(5.20 \mathrm{mg} / \mathrm{dl}$ versus $7.33 \mathrm{mg} / \mathrm{dl}, P<0.05)$ and women $(6.10 \mathrm{mg} / \mathrm{dl}$ versus $8.11 \mathrm{mg} / \mathrm{dl}$ ). The distribution of $\mathrm{Lp}(\mathrm{a})$ was relatively unaffected by menopause and cardiovascular disorders, including hypertension, diabetes mellitus, coronary heart disease and stroke. However, women taking oral contraceptives had significantly lower age-adjusted 
Table 3

Spearman correlation coefficients, $\gamma$, between lipoprotein(a) levels and various lipid and obesity profiles in the study population: the ChinShan Community Cardiovascular Cohort study, 1990-1991

\begin{tabular}{lccccc}
\hline Covariates & \multicolumn{2}{c}{ Male } & \multicolumn{3}{c}{ Female } \\
\cline { 2 - 3 } \cline { 5 - 6 } & Number & $\gamma$ & & Number & $\gamma$ \\
\hline Age & 1624 & $0.122^{* *}$ & & 1859 & $0.078^{* *}$ \\
BMI & 897 & $-0.122^{* *}$ & & 1127 & $-0.065^{*}$ \\
WHR & 985 & $-0.063^{*}$ & & 1224 & 0.014 \\
Systolic blood pres- & 1617 & 0.018 & & 1849 & 0.007 \\
$\quad$ sure & & & & \\
Diastolic blood pres- & 1617 & -0.045 & & 1849 & -0.034 \\
$\quad$ sure & & & & \\
Cholesterol & 1621 & $0.104^{* *}$ & & 1857 & $0.131^{* *}$ \\
Triglyceride & 1620 & $-0.120^{* *}$ & & 1857 & $-0.090^{* *}$ \\
HDL-C & 1599 & 0.038 & & 1844 & 0.045 \\
LDL-C & 1596 & $0.117^{* *}$ & & 1837 & $0.123^{* *}$ \\
Apo A1 & 1064 & -0.049 & 1350 & 0.025 \\
Apo B & 1063 & -0.014 & 1350 & -0.002 \\
\cline { 1 - 2 } & & & & \\
\hline
\end{tabular}

$* P<0.05$.

** $P<0.001$.

$\mathrm{Lp}$ (a) levels than women who did not take them $(4.55$ $\mathrm{mg} / \mathrm{dl}$ versus $7.78 \mathrm{mg} / \mathrm{dl}, P<0.05)$.

The Spearman correlations between Lp(a) and lipid profiles and other atherosclerotic risk factors are presented by gender in Tables 3 and 4. For both sexes, $\mathrm{Lp}(\mathrm{a})$ had significant positive correlations with age, total cholesterol and low-density cholesterol, and significant negative correlations with body-mass index, triglycerides and plasminogen activator inhibitors

\section{Table 4}

Spearman correlation coefficients between lipoprotein(a) levels and various atherosclerotic risk-factor profiles in the study population: the Chin-Shan Community Cardiovascular Cohort study in Taiwan, 1990-1991

\begin{tabular}{|c|c|c|c|c|}
\hline \multirow[t]{2}{*}{ Covariates $^{\mathrm{a}}$} & \multicolumn{2}{|l|}{ Male } & \multicolumn{2}{|l|}{ Female } \\
\hline & Number & $\gamma$ & Number & $\gamma$ \\
\hline \multirow[t]{3}{*}{$\mathrm{AC}$ insulin } & 925 & & 1194 & -0.047 \\
\hline & & - & & \\
\hline & & $0.140^{* * *}$ & & \\
\hline $\mathrm{PC}$ insulin & 897 & $-0.099 * *$ & 1154 & -0.037 \\
\hline AC glucose $(\mathrm{mg} / \mathrm{dl})$ & 933 & $-0.107^{* *}$ & 1195 & -0.019 \\
\hline FVII antigen & 1004 & -0.000 & 1171 & -0.009 \\
\hline FVIII & 1006 & 0.033 & 1169 & 0.004 \\
\hline TPA & 1006 & $-0.065^{*}$ & 1171 & -0.043 \\
\hline PAI & 1006 & $-0.093 * *$ & 1171 & $-0.075^{* *}$ \\
\hline Fibrinogen & 1006 & $0.154 * * *$ & 1171 & 0.007 \\
\hline
\end{tabular}

a AC, fasting; PC, $2 \mathrm{~h}$ post $75 \mathrm{~g}$ glucose intake; FVII, factor VII; FVIII, factor VIII; TPA, tissue plasminogen activator; PAI-1, plasminogen activator inhibitor.

$* P<0.05$.

** $P<0.01$

*** $P<0.001$.
Table 5

Multivariate model by Mallows' $\mathrm{C}(\mathrm{p})$ criteria of variable selection

\begin{tabular}{|c|c|c|c|}
\hline Covariate $^{\mathrm{a}}$ & $\beta$ & S.E. & $P$ value \\
\hline Intercept & 2.071 & 0.042 & 0.0001 \\
\hline Age $(65-74$ vs. $35-44)$ & 0.164 & 0.081 & 0.0427 \\
\hline $\begin{array}{l}\mathrm{TG}(\geqq 200 \mathrm{mg} / \mathrm{dl} \text { vs. }<200 \mathrm{mg} / \\
\mathrm{dl})\end{array}$ & -0.349 & 0.092 & 0.0002 \\
\hline $\begin{array}{l}\text { HDL }(<35 \mathrm{mg} / \mathrm{dl} \text { vs. } \geqq 35 \mathrm{mg} / \\
\text { dl) }\end{array}$ & -0.166 & 0.081 & 0.0403 \\
\hline $\begin{array}{l}\text { LDL }(\geqq 160 \mathrm{mg} / \mathrm{dl} \text { vs. }<160 \mathrm{mg} / \\
\text { dl) }\end{array}$ & 0.310 & 0.066 & 0.0001 \\
\hline $\begin{array}{l}\text { BMI ( } \geqq 75 \text { th percentile vs. }< \\
\text { 75th percentile) }\end{array}$ & -0.162 & 0.074 & 0.029 \\
\hline $\begin{array}{l}\text { HOMA ( } \geqq 75 \text { th percentile vs. }< \\
75 \text { th percentile) }\end{array}$ & -0.182 & 0.074 & 0.0141 \\
\hline Intercept & 2.039 & 0.040 & 0.0001 \\
\hline Age $(65-74$ vs. $35-44)$ & 0.168 & 0.081 & 0.0373 \\
\hline $\begin{array}{l}\mathrm{TG}(\geqq 200 \mathrm{mg} / \mathrm{dl} \text { vs. }<200 \mathrm{mg} / \\
\mathrm{dl})\end{array}$ & -0.365 & 0.092 & 0.0001 \\
\hline $\begin{array}{l}\text { HDL }(<35 \mathrm{mg} / \mathrm{dl} \text { vs. } \geqq 35 \mathrm{mg} / \\
\quad \text { dl) }\end{array}$ & -0.188 & 0.080 & 0.0194 \\
\hline $\begin{array}{l}\text { LDL }(\geqq 160 \mathrm{mg} / \mathrm{dl} \text { vs. }<160 \mathrm{mg} / \\
\text { dl) }\end{array}$ & 0.300 & 0.066 & 0.0001 \\
\hline $\begin{array}{l}\text { BMI }(\geqq 90 \text { th percentile vs. }< \\
\text { 90th percentile) }\end{array}$ & -0.296 & 0.100 & 0.0032 \\
\hline $\begin{array}{l}\text { HOM ( } \geqq 90 \text { th percentile vs. }< \\
\text { 90th percentile) }\end{array}$ & -0.152 & 0.101 & 0.1311 \\
\hline
\end{tabular}

${ }^{a}$ Covariates are: sex, age (45-54 years old versus 35-44 years old), age (55-64 years old versus 35-44 years old), age (64-74 years old versus 35-44 years old), age ( $\geqq 75$ years old versus $35-44$ years old), hypercholesterolemia, hypertriglyceridemia, low HDL-C, high LDLC, obesity, high WHR, diabetes status, hypertension status, insulin resistance index by homeostatsis modelling HOMA.

(Table 3). Lp(a) was negatively associated with apo A1 and apo B levels, but was not significant. We also found significant negative relationships between $\mathrm{Lp}(\mathrm{a})$ and serum insulin profiles, fasting glucose, TPA and PAI-1 for men, and PAI-1 for women (Table 4). The $\mathrm{Lp}$ (a) level was significantly correlated with fibrinogen (0.154, $P<0.001)$ among males only.

The multivariate model obtained from Mallows' C(p) showed that factors significantly associated with the $\mathrm{Lp}$ (a) level included older age groups, triglyceride (200 $\mathrm{mg} / \mathrm{dl}$ versus $<200 \mathrm{mg} / \mathrm{dl})$, HDL-C $(<35 \mathrm{mg} / \mathrm{dl}$ versus $35 \mathrm{mg} / \mathrm{dl})$, LDL $(160 \mathrm{mg} / \mathrm{dl}$ versus $<160 \mathrm{mg} / \mathrm{dl})$ and high BMI (Table 5). Triglyceride and LDL were the most significant influential factors. Hyperinsulinemia influence would become significant if the cut-off for this variable was set at the 75 th percentile in this model.

\section{Discussion}

The $\mathrm{Lp}(\mathrm{a})$ and other blood-chemistry measured for 3602 native Taiwanese men and women in the population-based study provided a unique opportunity to observe how $\mathrm{Lp}(\mathrm{a})$ is associated with other atheroscle- 
rotic risk factors in this Chinese population. The distribution of $\mathrm{Lp}$ (a) was skewed to the right, similar to that found for Caucasians [1,7], higher in females than in males, and positively correlated with age. The range of $\mathrm{Lp}$ (a) levels for this study population seemed similar to that for the Framingham offspring [7], and significantly lower than that for Japanese and black populations $[23,24]$.

A limited number of studies have reported the median values of $\mathrm{Lp}$ (a) for other Chinese ethnic groups, ranging from $7.0 \mathrm{mg} / \mathrm{dl}$ for Chinese in Singapore to $25.0 \mathrm{mg} / \mathrm{dl}$ for Chinese in Hong Kong [3,12]. However, those measures were based on small sample sizes between 30 and 304. To our knowledge, this study was the largest study based on a healthy Chinese community, and based on a large-scale population.

The relationships between $\mathrm{Lp}(\mathrm{a})$ and other atherosclerotic risk factors vary among studies $[7,8,23-$ 27]. Studies based on the Japanese population have demonstrated significant correlations between $\mathrm{Lp}(\mathrm{a})$ and cholesterol and LDL-C levels[23,25]. We did observe striking differences in $L p(a)$ distributions by lipid profiles; the average $\mathrm{Lp}(\mathrm{a})$ levels were elevated for individuals with hypercholesterolemia and high LDL-C levels in both genders. However, several studies report a negative correlation between levels of $\mathrm{Lp}$ (a) and triglyceride [7,23,28-30]. Since hypercholesterolemia, high LDL-C, low HDL-C and/or hypertriglyceridemia have been considered important atherosclerotic risk factors, much of the relationship between $\mathrm{Lp}(\mathrm{a})$ and these lipid profiles remains to be understood, particularly concerning the control of $\mathrm{Lp}(\mathrm{a})$ metabolism and its role in atherosclerosis. The negative correlation between $\mathrm{Lp}(\mathrm{a})$ and triglyceride levels and the positive correlation between Lp(a) and LDL-C levels are puzzling and deserve further investigation.

Because of common metabolic pathways for insulin resistance syndrome, including hypertriglyceridemia, low HDL-C, and obesity, we observed a strong negative correlation between $\mathrm{Lp}(\mathrm{a})$ and insulin, glucose and insulin-related metabolic factors. Regardless of whether hyperinsulinemia was defined as above the 75 th percentile or the 90th percentile of fasting insulin levels for the population, the average $\mathrm{Lp}$ (a) was significantly lower in hyperinsulinemic males than in non-hyperinsulinemic males. A similar pattern was observed for females, but not as significantly as that for males. The Lp(a) level and obesity also exhibited a similar gender-specific pattern. This finding may explain the gender difference in the pathogenesis of atherogenesis as noted in other studies [31,32] and may imply that some complex mechanisms associating $\mathrm{Lp}$ (a) with insulin resistance syndrome deserve further investigation.

In our studies, blood pressure levels and the presence of hypertension, diabetes mellitus, coronary heart disease and stroke status did not have significant correla- tions with $\mathrm{Lp}(\mathrm{a})$ levels. Other studies suggest coronary artery disease events are related to excess $L p(a)$ levels [33-35], but definitive causation is unproved, and may be due to population-specific characteristics.

The $L p(a)$ level may be elevated for women in the menopause and lowered for those with oral estrogen. The menopausal association was not as significant in the Framingham Offspring study and the Japanese study [7,23], but was significant in the Northern Sweden MONICA study [8]. In our study, menopausal status had no influence on Lp(a) levels. However, women who took oral contraceptives may have been younger and, therefore, had significantly lowered age-adjusted Lp(a) levels than women who did not use oral contraceptives. Similar results were also reported by Lobo et al. [36].

In the coagulation profiles study, we found that in males, the $\mathrm{Lp}$ (a) level was closely correlated with fibrinogen levels, but inversely correlated with TPA and PAI-1. In females, only PAI-1 levels were inversely significantly correlated with $\mathrm{Lp}(\mathrm{a})$ levels. $\mathrm{Lp}(\mathrm{a})$ is presumed to be a dual risk factor for both atherogenesis and thrombosis, and may play different roles in males and females. Other studies reported significant associations between $\mathrm{Lp}$ (a) levels and fibrinogen levels in females rather than in males $[23,37,38]$. In this study, a significant association between $\mathrm{Lp}(\mathrm{a})$ and fibrinogen level was found for males only. This gender discrepancy may underscore the pathogenesis of $\mathrm{Lp}$ (a) thrombosis in different sexes.

In conclusion, this community-based population study showed that Lp(a) levels were: (i) higher in women than in men; (ii) positively associated with atherosclerotic risk factors such as LDL-C, and negatively associated with HDL-C and triglyceride; and (iii) positively associated with selected coagulation profiles such as fibrinogen, and negatively associated with TPA and PAI. Lp(a) levels had no strong association with coronary heart disease, stroke, hypertension, and diabetes mellitus. However, individuals with the insulin resistance syndrome, including those with high triglyceride, low HDL-C, obesity and high insulin levels, levels tended to have lowered $\mathrm{Lp}$ (a) level. These relationships in $\mathrm{Lp}(\mathrm{a})$ atherosclerosis and thrombosis pathogenesis should be explored further, using longitudinal data that will be available from our Chin-Shan cohort in the next few years.

\section{Acknowledgements}

We thank cardiologists at National Taiwan University Hospital, Yu-Jenn Huang and Ching-Chu Chien for their assistance in this study. The study was partly supported by the Department of Health (Grant \# DOH82-TD-068) and National Scientific Council (Grant \# NSC 83-0412-B002-064). 


\section{References}

[1] Utermann G. The mysteries of lipoprotein (a). Science 1989;246:904-10.

[2] Zenker G, Koltringer P, Bone G, Niederkorn K, Pfeiffier K, Jurgens G. Lipoprotein(a) as a strong indicator for cerebrovascular disease. Stroke 1986;17:942-5.

[3] Sandholzer C, Saha N, Kark JD, Rees A, Jaross W, Dieplinger H, Hoppichler F, Boerwinkle E, Ultermann G. Apo(a) isoforms predict risk for coronary heart disease. A study in six populations. Arterioscler Thromb 1992;12:1214-26.

[4] McLean JW, Tomlinson JE, Kuang WJ, Eaton DL, Chen EY, Fless GM, Scanu AM, Lawn RM. cDNA sequence of human apolipoprotein(a) is homologous to plasminogen. Nature 1987;330:132-7.

[5] Mori J, Sasaki J, Kawaguchi H, Handa K, Takada Y, Matsunaga A, Kono S, Arakawa K. Serum glycoproteins and severity of coronary atherosclerosis. Am Heart J 1995;129(2):234-8.

[6] Scanu lipoprotein (a) and atherosclerosis. Ann. J. Med. 1991;115:209-218

[7] Jenner JL, Ordovas JM, Lamon-Fava S, Schaefer MM, Wwilson PWF, Castelli WP, Schaefer EJ. Effects of age, sex and menopausal status on plasma lipoprotein(a) levels. The Framingham Offspring Study. Circulation 1993;87:1135-41.

[8] Slunga L, Asplund K, Johnson O, Dahlen GH. Lipoprotein(a) in a randomly selected 25-64 year old population: The Northern Sweden MONICA Study. J Clin Epidemiol 1993;46:617-24.

[9] Brown SA, Hutchinson R, Morrisett J, Boerwinkle E, Davis CE, Gotto AM Jr. Patsch W. Plasma lipid, lipoprotein cholesterol, and apoprotein distributions in selected US communities. Arterioscler Thromb 1993;13:1139-58.

[10] Gurakar A, Hoeg JM, Kostner G, Papadopoulos NM, Brewer HB Jr. Levels of lipoprotein Lp(a) decline with neomycin and niacin treatment. Atherosclerosis 1985;57:293-301.

[11] Sandholzer C, Saha N, Kark JD, Ree A, Jaross W, Dieplinger H, Hoppichler F, Boerwinkle E, Utermann G. Apo(a) isofroms predict risk for coronary heart disease. A study in six populations. Artherioscler Thromb 1992;12:1214-26.

[12] Woo J, Lam CW. Association of serum lipoprotein(a) concentration with other cardiovascular risk factors in a Chinese population. J Clin Lab Anal 1991;5(5):335-9.

[13] Cobbaert C, Kesteloot H. Serum lipoprotein(a) levels in racially different populations. Am J Epidemiol 1992;136(4):441-9.

[14] Taiwan: Reports of Department of Health. Executive Yuan, Republic of China. Taipei, Taiwan. 1995:134-147.

[15] Chung MY, Jeng JS, Yip PK. Study on blood lipids, lipoproteins, and apolipoproteins in different types of ischemic stroke. Acta Neurol Sin 1994;3:194-9.

[16] Wieland H, Seidel D. A simple specific method for precipitation of low density lipoproteins. J Lipid Res 1983;24:904-9.

[17] Walford S. Insulin measurement. Pract Diabetes 1989;6:56-8.

[18] Shen MC. One hundred and two cases of hemophilia A in Taiwan I. Clinical, laboratory and family studies. J Formosan Med Assoc 1982;81:190-206.

[19] Joint National Committee. The fifth report of the Joint National Committee on Detection, Evaluation and Treatment of High Blood Pressure (JNC V). Arch Intern Med 1993;153:154-83.

[20] Matthws DR, Hosker JP, Rudenski AS, Naylor BA, Treacher DF, Turner RC. Homeostasis model assessment: insulin resistance and -cell function from fasting plasma glucose and insulin concentrations in man. Diabetologia 1985;28:412-9.
[21] Mallows CP. Some comments on $\mathrm{C}_{\mathrm{p}}$. Technometrics 1973; 15:661-75.

[22] SAS Institute. SAS/STAT software: changes and enhancements through Release 6.11. Cary, NC: SAS Institute, 1996:1104 pp.

[23] Nago N, Kayaba K, Hiraoka J, Matuso H, Goto T, Kario K, Tsutsumi A, Nakamura Y, Igarashi M. Lipoprotein(a) levels in the Japanese Population: Influences of age and sex, and relation to atherosclerotic risk factors. Am J Epidemiol 1995;141:815-21.

[24] Howard BV, Le NA, Belcher JD, Flack JM, Kacobs DR, Lewis CE, Marcovina SM, Perkins LL. Concentrations of Lp(a) in Black and white young adults: relations to risk factors for cardiovascular disease. Ann Epidemiol 1994;4:341-50.

[25] Kario K, Matuo T, Imiya M, Kayaba K, Kuroda T, Nago N, Matsuo H, Shimada K. Close relation between lipoprotein (a) levels and atherosclerotic disease in Japanese subjects $>75$ years of age. Am J Cardiol 1994;73:1187-90.

[26] Schreiner PJ, Heiss G, Tyroler HA, Morrisett JD, Kavis CE, Smith R. Race and gender differences in the association of $\mathrm{Lp}(\mathrm{a})$ with carotid artery wall thickness. The Atherosclerosis Risk in Communities (ARIC) Study. Arterioscler Thromb Vasc Biol 1996;16:471-8.

[27] Anderson AJ, Sobocinski KA, Freedman DS, Barboriak JJ, Rimm AA, Gruchow HW. Body fat distribution, plasma lipids, and lipoproteins. Arteriosclerosis 1988;8:88-94.

[28] De Pergola G, Giorgino F, Cospite MR, Giagulli VA, Cignarelli M, Ferri G, Giorgino R. Relation between sex hormones and serum lipoprotein and lipoprotein(a) concentrations in premenopausal obese women. Arterioscler Thromb 1993;13:675-9.

[29] Bartens W, Rader DJ, Talley G, Brewer B Jr. Decreased plasma levels of lipoprotein(a) in patients with hypertriglyceridemia. Atherosclerosis 1994;108:149-57.

[30] Assmann G, Schulte H, Eckardstein A. Hypertriglyceridemia and elevated lipoprotein(a) are risk factors for major coronary events in middle-aged men. Am J Cardiol 1996;77:1179-84.

[31] Leaf DA. Women and coronary artery disease: gender confers no immunity. Postgrad Med 1990;87:55-60.

[32] Krolewski AS, Warram JH, Valsania P, Martin BC, Laffel LMB, Christlieb R. Evolving natural history of coronary artery disease in diabetes mellitus. Am J Med 1991;90(Suppl 2A):56S$61 \mathrm{~S}$.

[33] Genest J, Jenner JL, McNamara JR, Ordovas JM, Silbermann SR, Wilson PW, Schaefer EJ. Prevalence of lipoprotein(a) excess in coronary heart disease. Am J Cardiol 1991;67:1039-45.

[34] Rhoads GG, Dahlen G, Berg K, Morton NE, Dannenberg AL. $\mathrm{Lp}$ (a) lipoprotein as a risk factor for myocardial infarction. $\mathrm{J}$ Am Med Assoc 1986;256:2540-4.

[35] Ridker PM, Hannekens CH, Stampfer MJ. A prospective study of lipoprotein (a) and the risk of myocardial infarction. J Am Med Assoc 1993;270:2195-9.

[36] Lobo RA, Notelovitz M, Bernstein L, Khan FY, Ross RK, Paul WL. Lp(a) lipoprotein: relationship to cardiovascular diseases risk factors, exercise, and estrogen. Am J Obstet Gynecol 1992;166:1182-90.

[37] Folsom AR, Wu KK, Davis CE, Conlan MG, Sorlie PD, Szklo M. Population correlates of plasma fibrinogen and factor VII, putative cardiovascular risk factors. Atherosclerosis 1991;91:191-205.

[38] Heinrich J, Sandkamp M, Kokott R, Schulte H, Assmann G. Relationship of lipoprotein(a) to variables to coagulation and fibrinolysis in a healthy population. Clin Chem 1991;37:19504. 